\title{
INDICADOR DE CONFIABILIDADE METROLÓGICA: INDICADOR DE AVALIAÇÃO DE OPERADORES NAS ANÁLISES QUE CARACTERIZAM MINÉRIO DE FERRO*
}

\author{
Rossana Bezerra de Azevedo Vasconcelos Seabra de Melo ${ }^{1}$ \\ Carla Schwengber ten Caten ${ }^{2}$ \\ Pablo Jordano Sacramento Mendes ${ }^{3}$ \\ Daniela Sedraz Silva de Freitas ${ }^{4}$ \\ Lisandra Carla Machado Costa Silva ${ }^{5}$
}

Resumo

O presente estudo apresenta um método de avaliação de desempenho de operadores nas análises químicas que caracterizam o minério de ferro. São eles: Ferro total $(\mathrm{Fe})$, sílica $\left(\mathrm{SiO}_{2}\right)$, alumina $\left(\mathrm{Al}_{2} \mathrm{O}_{3}\right)$, manganês $(\mathrm{Mn})$, fósforo $(\mathrm{P})$ e perda por calcinação (PPC). O desempenho é avaliado em termos de precisão e veracidade. Estes dois indicadores primários são combinados num secundário denominado de indicador de "confiabilidade metrológica". O método foi aplicado nos laboratórios da Mina (no estado do Pará) e do Porto (no estado do Maranhão) de uma empresa mineradora onde foi possível: 1) conhecer o desempenho de cada laboratório assim como conhecer o desempenho de cada operador; 2) identificar os pontos fortes (identificar 0 procedimento que leva a melhores desempenhos) e oportunidades de melhorias (atuar nas causas, capacitar); 3) equalizar a forma de executar cada uma das tarefas com as melhores práticas identificadas; 4) proporcionar oportunidade de desenvolvimento técnico dos profissionais envolvidos no processo. O desempenho neste indicador tornou-se critério avaliação de aptidão para executar análises.

Palavras-chave: Análise de minério de ferro; Indicador de desempenho; Precisão e veracidade.

\section{METROLOGICAL RELIABILITY INDICATOR: INDICATOR ASSESSMENT OF OPERATORS IN ANALYSIS FEATURING IRON ORE}

\section{Abstract}

This study presents a method for evaluating the performance of operators in the chemical analyzes that characterize the iron ore. These include: Total iron $(\mathrm{Fe})$, silica $\left(\mathrm{SiO}_{2}\right)$, alumina $\left(\mathrm{Al}_{2} \mathrm{O}_{3}\right)$, manganese $(\mathrm{Mn})$, phosphorus $(\mathrm{P})$ and loss on ignition (PPC). The performance is evaluated of precision and accuracy were defined. These indicators are then combined into an overall performance indicator "metrological reliability". The method was applied in the Mine laboratories (Pará/Brazil) and Porto (Maranhão/Brazil) of a mining company where it was possible to: 1 ) understand the performance of each laboratory, on the performance of each operator, 2) identify strengths (identify the procedure that leads to better performance) and opportunities for improvement (acting on the causes), 3) equalize how to perform each of the tasks by applying identified best practices, 4) provide an opportunity for technical development of professionals involved in the process. The performance for this indicator has become an evaluation criterion of aptitude to perform those analyzes.

Keywords: Analysis of iron ore; An indicator of performance; Precision and accuracy.

Eng. Química, Eng. Química, Resp. Técnica por laboratório do Sistema Norte, Vale, São Luís, MA, Brasil.

Dra. Eng. de Materiais, Msc Eng.Produção, Vice Diretora da Escola de Engenharia, UFRGS, Porto Alegre, RS, Brasil.

3 Administrador, Gerente de Área de Desenvolvimento, Otimização de Processo e Laboratórios, Vale, Carajás, PA, Brasil.

4 Eng. Química, Resp. Técnica por laboratório do Sistema Norte, Vale, Carajás, PA, Brasil.

5 Administradora, Analista Operacional de Laboratório, Vale, São Luís, MA, Brasil.

\footnotetext{
* Contribuição técnica ao 44ํㅗㄴ Seminário de Redução de Minério de Ferro e Matérias-primas, 15ㅇ Simpósio Brasileiro de Minério de Ferro e 2 Simpósio Brasileiro de Aglomeração de Minério de Ferro, 15 a 18 de setembro de 2014, Belo Horizonte, MG, Brasil.
} 


\section{INTRODUÇÃO}

Em um ambiente competitivo, faz-se necessário criar ferramentas de avaliação do processo e das pessoas por ele responsáveis, de forma a medir seu desempenho e dar subsídio para implantação de melhorias contínuas, na busca pela excelência.

A melhoria da qualidade, representada pela redução da variabilidade do processo, promove um aumento de produtividade, à medida que aumenta a probabilidade de geração de itens/ análises conformes. A melhoria da qualidade também leva a uma diminuição de custos, devido à redução do retrabalho, erros e atrasos, e da melhor utilização da tecnologia e matéria-prima. Consequentemente, a produtividade aumenta. Mais especificamente no controle de qualidade de empresas mineradoras, faz-se necessário garantir a confiabilidade dos resultados analisados por não se tratar de um controle de qualidade de produto beneficiado, mas sim, da caracterização da qualidade do minério que é utilizado para calculo do faturamento da empresa (exportação de minério no porto). A qualidade das analises também é importante para caracterização das reservas geológicas, o que impacta no valor das ações da empresa nas bolsas de valores (caracterização de reservas geológicas na mina), assim como para dar subsídio a tomadas de ação estratégicas para empresa quanto a produção de minério/ seleção de frentes de lavras (produção de minério na mina) .

A criação do indicador "confiabilidade metrológica" foi inicialmente planejada e sofreu evoluções ao longo do tempo. Definido como seria o processo de avaliação, passou-se a controlar o indicador. De posse de informações iniciais, foi possível identificar os pontos fortes e oportunidades de melhoria, assim como iniciar ações de gestão para melhorias. Com uma sistemática de gestão definida, iniciou-se a adoção de otimização de processos por meio de padronizações de detalhes na execução das análises e a implantação de novas tecnologias que propiciaram maior exatidão às análises.

Os operadores foram avaliados mensalmente. A cada um deles foram entregues cinco materiais de referencia (MR) duplicados, o que resultou em dez amostras, que foram codificadas aleatoriamente.

Uma análise minuciosa dos dados foi feita por análise e por operador, de onde se obtiveram informações valiosas para gestão do processo e gestão de pessoas. Diálogos individualizados foram feitos com o objetivo de identificar oportunidade de melhoria, esclarecer dúvidas técnicas de forma equalizar método de análise, 0 conhecimento e, consequentemente, melhorar a qualidade do serviço analítico prestado.

O trabalho está estruturado em cinco seções, incluindo a presente introdução. A seção 2 apresenta o referencial teórico sobre a avaliação de precisão e veracidade. A seção 3 apresenta o método utilizado e na seção 4 , resultados e discussões. $\mathrm{Na}$ seção 5 estão as conclusões do estudo, bem como a aplicação dos resultados em benefício do laboratório.

\subsection{Revisão da Literatura: Análises Realizadas no Minério de Ferro}

\subsection{1 - Análise do teor de Ferro}

A análise do teor de Ferro se dá por via úmida costuma ser feita com base na Norma 2597-2 - Minérios de ferro - Determinação do teor de ferro total Parte 2: Métodos de titulação após redução de cloreto de titânio (III).

\footnotetext{
* Contribuição técnica ao 44 Seminário de Redução de Minério de Ferro e Matérias-primas, $15^{\circ}$ Simpósio Brasileiro de Minério de Ferro e 2 Simpósio Brasileiro de Aglomeração de Minério de Ferro, 15 a 18 de setembro de 2014, Belo Horizonte, MG, Brasil.
} 
Para a determinação deste teor, utiliza-se dicromato de potássio como titulante depois da redução do ferro (III) pelo cloreto de estanho (II) e cloreto de titânio (III). O excesso de agente redutor é então oxidado pelo dicromato de potássio diluído.

$\mathrm{Na}$ batelada de ensaios executados na rotina da empresa analisada no estudo de caso, três amostras de um mesmo padrão certificado são utilizadas para calcular o fator da Solução $\mathrm{K}_{2} \mathrm{Cr}_{2} \mathrm{O}_{7} 0,1 \mathrm{~N}$, através da fórmula:

$$
f=\frac{\% F e \times m}{V}
$$

Onde:

$f=$ Fator da solução de $\mathrm{K}_{2} \mathrm{Cr}_{2} \mathrm{O}_{7} 0,1 \mathrm{~N}$

$\% \mathrm{Fe}=$ Valor certificado do padrão de fatoração

$\mathrm{m}=$ massa da amostra

$\mathrm{V}=$ volume gasto na titulação

Calcula-se o \% Fe o, utilizando a fórmula:

$$
\% F e=\frac{f \times V}{m}
$$

A aplicação deste método de análise via úmida é recomendado pela Norma na faixa de concentração de $30 \%$ a $72 \%$ de ferro em concentrados e aglomerados de minério de ferro.

\subsection{2 - Análise de contaminantes de minério de ferro por meio de fluorescência de} raio-X: sílica $\left(\mathrm{SiO}_{2}\right)$, alumina $\left(\mathrm{Al}_{2} \mathrm{O}_{3}\right)$, manganês $(\mathrm{Mn})$, fósforo $(\mathrm{P})$.

A análise por fluorescência de raio-X (FRX) está baseada na norma ISO 9516 Determinação de vários elementos. Esta norma contempla desde como devem ser confeccionadas as pastilhas de minério até a definição de comprimento de onda específico para cada elemento.

É um método qualitativo e quantitativo muito recomendado para determinação da composição química em minérios.

O método consiste em irradiar um feixe de raios $X$ na amostra preparada, provocando deslocamento de um elétron das camadas mais internas do átomo. Então, para substituir o elétron perdido, outro elétron salta de uma das camadas mais externas liberando energia na forma de raios $X$ fluorescentes, emitidos em comprimentos de onda característicos de cada elemento. A figura 1 ilustra esse fenômeno.

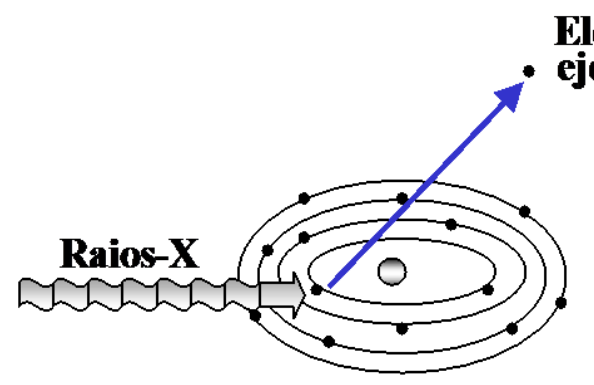

$\mathbf{A}$

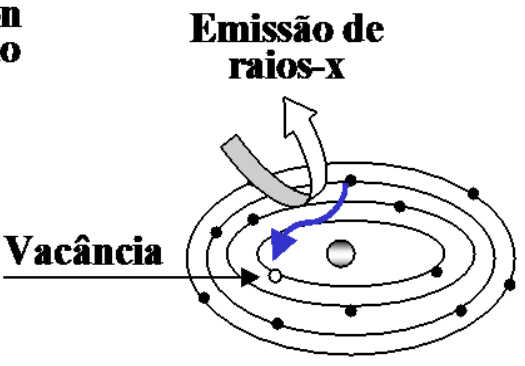

B

Figura 1 - Fluorescência de raios $X$

(A) Efeito Fotoelétrico

(B) Emissão de Raios-X característicos provenientes e transições eletrônicas subsequentes

* Contribuição técnica ao 44 Seminário de Redução de Minério de Ferro e Matérias-primas, 15 Simpósio Brasileiro de Minério de Ferro e 2o Simpósio Brasileiro de Aglomeração de Minério de Ferro, 15 a 18 de setembro de 2014, Belo Horizonte, MG, Brasil. 
A transição denominada $\mathrm{K}_{\alpha}$ representa o raio- $\mathrm{X}$ liberado após o preenchimento de uma lacuna na camada $\mathrm{K}$ por um elétron da camada $\mathrm{L}$; $\mathrm{K}_{\beta}$ originou-se da ocupação da lacuna da camada $\mathrm{K}$ por um elétron da $\mathrm{M}$ e assim por diante.

\subsection{3 - Determinação de Perda por Calcinação (PPC).}

A medida de perda por calcinação (PPC) de minério de ferro, também conhecida como perda ao fogo, representa o percentual de água estrutural, ou seja, a presença de goethita $(\mathrm{FeO}(\mathrm{OH}))$, e de material orgânico na amostra. Este é um parâmetro extremamente importante para prever o comportamento do minério dentro dos altos fornos.

O ensaio de determinação de perda por calcinação ainda não tem norma oficial na ISO, mas já foi submetido ao comitê uma solicitação de criação da norma (ISO/CD 11536), na qual descreve o procedimento para determinação deste parâmetro em minério de ferro oxidado, pelo método gravimétrico. Esse procedimento é o aplicado pela maioria dos laboratórios e consiste em submeter a amostra, previamente seca em estufa por uma hora (livre de água superficial) e, na sequência submeter a $1.000^{\circ} \mathrm{C}$, em forno, durante uma hora (para retirada da água estrutural). Vale ressaltar que o cadinho deve ser pré-calcinado, antes do início da análise, para garantir não haja interferência na medida do peso do cadinho vazio.

A fórmula de cálculo de PPC é a seguinte:

Onde:

$$
\% P P C=\frac{\left(P_{2}-P_{3}\right)}{\left(P_{2}-P_{1}\right)}
$$

$\mathrm{P} 1$ = massa do cadinho pré-calcinado

$\mathrm{P} 2$ = massa da amostra seca + cadinho

P3 = massa da amostra calcinada + cadinho

\subsection{Indicadores de Desempenho: Veracidade e Precisão}

\subsection{1 - Avaliação de veracidade}

Veracidade é o grau de concordância entre a média de um número infinito de valores medidos repetidos e um valor de referência. A veracidade está inversamente relacionada ao erro sistemático.

Para esta aplicação, a veracidade é determinada através do cálculo do erro relativo ao valor certificado dos diferentes MR utilizados na avaliação. É expresso o quanto o valor analisado está distante do valor certificado.

$$
\% E R=\frac{(V A-V C)}{(V C)} \times 100
$$

Onde:

$\% \mathrm{ER}=\%$ de erro relativo

$\mathrm{VA}=$ Valor analisado

$\mathrm{VC}=$ Valor certificado

É importante explicar que o termo "veracidade" difere de "exatidão" porque este se refere a apenas uma medida, enquanto a veracidade se refere a um grande numero de medidas, de acordo com o VIM (Vocabulário Internacional de Metrológica).

\footnotetext{
* Contribuição técnica ao $44^{\circ}$ Seminário de Redução de Minério de Ferro e Matérias-primas, $15^{\circ}$ Simpósio Brasileiro de Minério de Ferro e 2 Simpósio Brasileiro de Aglomeração de Minério de Ferro, 15 a 18 de setembro de 2014, Belo Horizonte, MG, Brasil.
} 


\subsection{2 - Avaliação de precisão}

Precisão é o grau de concordância entre indicações ou valores medidos, obtidos por medições repetidas, no mesmo objeto ou em objetos similares, sob condições especificadas.

Uma das diferentes formas de se medir precisão é estimar o desvio-padrão a partir das diferenças entre duas medidas de diferentes materiais similares.

Para se estimar o desvio-padrão, calcula-se a amplitude média do processo de medição, simbolizada por $\bar{R}$, que é igual à soma das amplitudes dos pares de medida dos diferentes materiais dividida pelo número de materiais analisados.

$$
\sigma^{2}=\left(\frac{\bar{R}}{d_{2}}\right)^{2}=(\bar{R} \times 0,8862)^{2} \quad \sigma=\bar{R} \times 0,8862
$$

Onde:

$\sigma=$ estimativa de desvio padrão

$\sigma^{2}=$ variância

$\bar{R}=$ é a amplitude média do processo

$1 / d_{2}=$ é o fator relacionado ao $n^{\circ}$ de medidas $=0,8862$ para um par de medidas.

\section{MATERIAIS E MÉTODOS: FORMAÇÃO DO INDICADOR SECUNDÁRIO "CONFIABILIDADE METROLÓGICA"}

O objetivo deste método é avaliar veracidade e precisão dos operadores e processo de dois laboratórios da empresa mineradora (laboratório de caracterização da mina e produção de minério de ferro no estado do Pará e laboratório de análise de carga de minério de ferro a ser exportado no porto no estado do Maranhão) para que se busque melhoria contínua nas análises.

\section{1 - Definição das Faixas para Classificação de Indicadores Primários: Precisão e Veracidade}

Para definição de níveis de classificação que refletem o desempenho dos operadores e do processo quanto à precisão e veracidade, utilizaram-se dados de carta de controle de cada um dos processos com os parâmetros hora estabelecidos, associados a algumas definições heurísticas, de forma a possibilitar pontuar "8" o que e considerado aceitável e ser exequível atingir o nível máximo que corresponde a pontuação "10".

Com este escalonamento, tornou-se possível avaliar individualmente o desempenho de cada operador e classificá-los, além de avaliar os processos de medição.

Nas tabelas 3 e 4 respectivamente, estão as classificações para desempenho em Precisão e Veracidade que, quando combinados em termos de pontuação, em igual proporção, geram o indicador secundário denominado de Confiabilidade Metrológica.

\footnotetext{
* Contribuição técnica ao 44 Seminário de Redução de Minério de Ferro e Matérias-primas, 15은 Simpósio Brasileiro de Minério de Ferro e 2 Simpósio Brasileiro de Aglomeração de Minério de Ferro, 15 a 18 de setembro de 2014, Belo Horizonte, MG, Brasil.
} 
Tabela 3 - Classificação de níveis de precisão

\begin{tabular}{|c|c|c|c|c|c|c|c|c|c|c|c|c|}
\hline \multirow[b]{3}{*}{ Nível 0} & \multicolumn{12}{|c|}{ PRECISÃO: ESTIMATIVA DE DESVIO-PADRÃO } \\
\hline & \multicolumn{2}{|c|}{$\mathrm{SiO} 2$} & \multicolumn{2}{|c|}{$\mathrm{P}$} & \multicolumn{2}{|c|}{$\mathrm{Al} 2 \mathrm{O} 3$} & \multicolumn{2}{|c|}{$\mathrm{Mn}$} & \multicolumn{2}{|c|}{ PPC } & \multicolumn{2}{|c|}{$\mathrm{Fe}$} \\
\hline & $>$ & 0,13 & $>$ & 0,0107 & $>$ & 0,07 & $>$ & 0,07 & $>$ & 0,14 & $>$ & 0,31 \\
\hline Nível 1 & 0,13 & 0,12 & 0,0107 & 0,0097 & 0,07 & 0,06 & 0,07 & 0,07 & 0,14 & 0,13 & 0,31 & 0,28 \\
\hline Nível 2 & 0,12 & 0,10 & 0,0097 & 0,0087 & 0,06 & 0,06 & 0,07 & 0,06 & 0,13 & 0,11 & 0,28 & 0,24 \\
\hline Nível 3 & 0,10 & 0,09 & 0,0087 & 0,0077 & 0,06 & 0,05 & 0,06 & 0,05 & 0,11 & 0,10 & 0,24 & 0,21 \\
\hline Nível 4 & 0,09 & 0,08 & 0,0077 & 0,0067 & 0,05 & 0,04 & 0,05 & 0,05 & 0,10 & 0,09 & 0,21 & 0,18 \\
\hline Nível 5 & 0,08 & 0,07 & 0,0067 & 0,0057 & 0,04 & 0,04 & 0,05 & 0,04 & 0,09 & 0,08 & 0,18 & 0,15 \\
\hline Nível 6 & 0,07 & 0,06 & 0,0057 & 0,0047 & 0,04 & 0,03 & 0,04 & 0,03 & 0,08 & 0,07 & 0,15 & 0,12 \\
\hline Nível 7 & 0,06 & 0,05 & 0,0047 & 0,0037 & 0,03 & 0,03 & 0,03 & 0,03 & 0,07 & 0,06 & 0,12 & 0,09 \\
\hline Nível 8 & 0,05 & 0,04 & 0,0037 & 0,0027 & 0,03 & 0,02 & 0,03 & 0,02 & 0,06 & 0,04 & 0,09 & 0,06 \\
\hline Nível 9 & 0,04 & 0,03 & 0,0027 & 0,0017 & 0,02 & 0,01 & 0,02 & 0,01 & 0,04 & 0,03 & 0,06 & 0,03 \\
\hline Nível 10 & $<$ & 0,03 & $<$ & 0,0017 & $<$ & 0,01 & $<$ & 0,01 & $<$ & 0,03 & $<$ & 0,03 \\
\hline
\end{tabular}

Tabela 4 - Classificação de níveis de veracidade

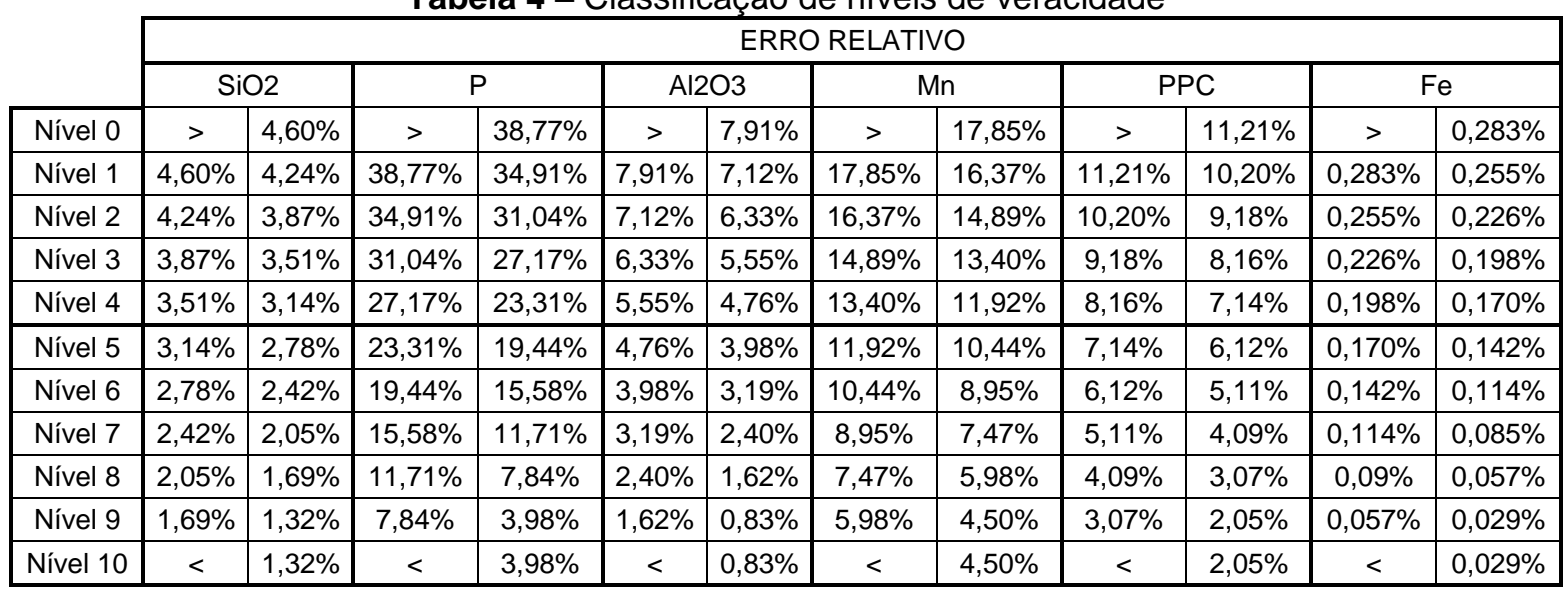

\section{RESULTADOS E DISCUSSÃO}

Conforme apresentado na seção 2, o desempenho dos operadores quanto à precisão e veracidade se deu por meio de classificação em níveis pré-definidos. Doze profissionais do laboratório do porto e dezoito profissionais do laboratório da mina foram avaliados comparativamente. Nos gráficos a seguir, estão demonstradas as evoluções de desempenho do indicador de confiabilidade metrológica onde as barras indicam a pontuação atingida no indicador, mês a mês, que consistem na média aritmética da pontuação obtida nos indicadores primários, em termos de precisão e veracidade de acordo com os critérios estabelecidos na seção 2.1 .

A meta, estabelecida aqui como 8, foi assim definida pelo fato de, na classificação dos indicadores primários, a pontuação "8" corresponder ao que se considera aceitável para realidade inicial do processo de medição e escalonado de forma a e ser exequível atingir o nível máximo que corresponde a pontuação "10".

\footnotetext{
* Contribuição técnica ao 44오 Seminário de Redução de Minério de Ferro e Matérias-primas, 15은 Simpósio Brasileiro de Minério de Ferro e 2 Simpósio Brasileiro de Aglomeração de Minério de Ferro, 15 a 18 de setembro de 2014, Belo Horizonte, MG, Brasil.
} 
MARANHÃO (porto)

Teor de ferro por via úmida

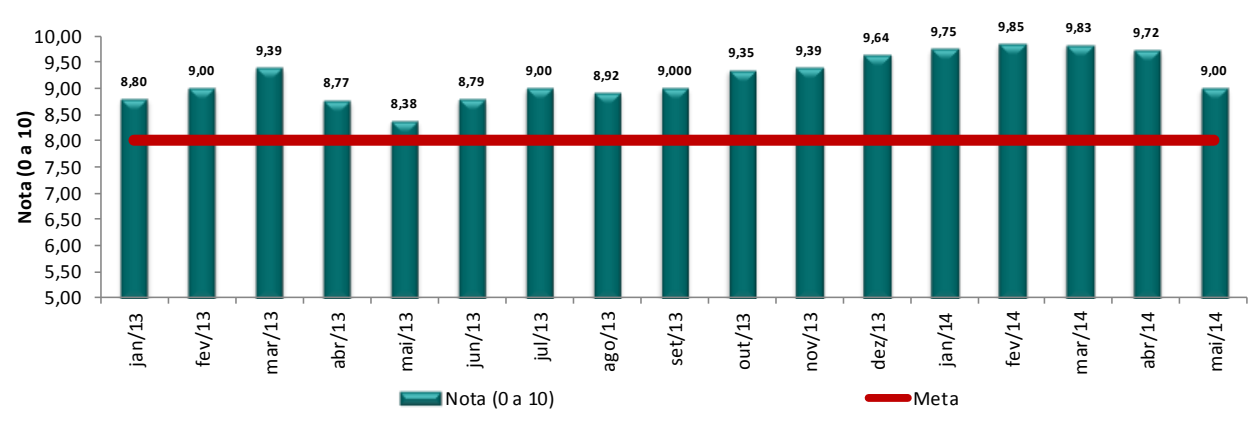

Teor de contaminantes por Raio-X

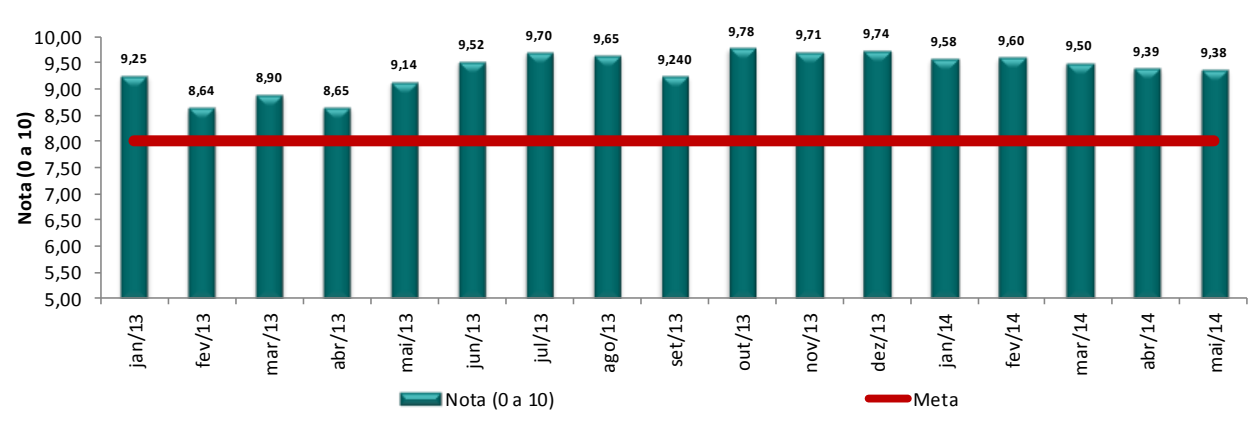

Teor de perda por calcinação (PPC)

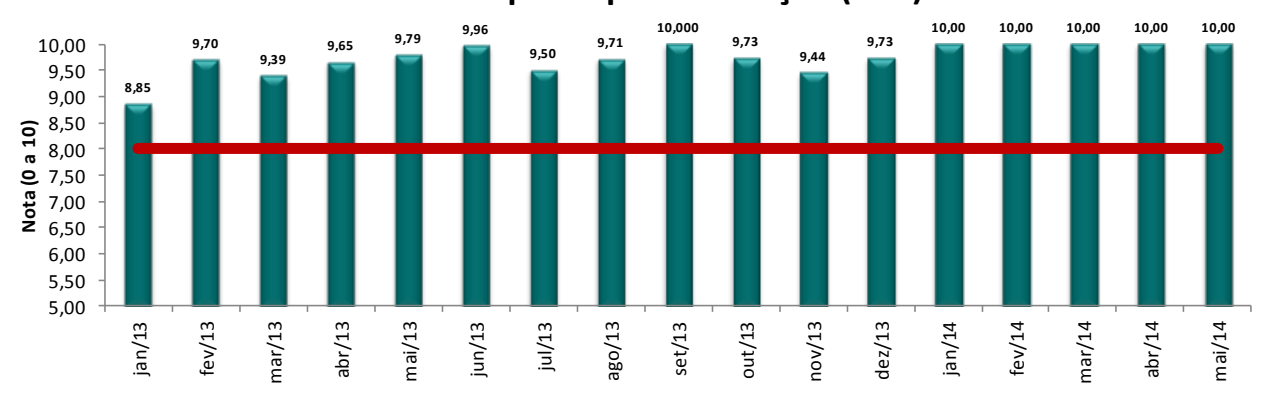

PARÁ (mina)

Teor de ferro por via úmida

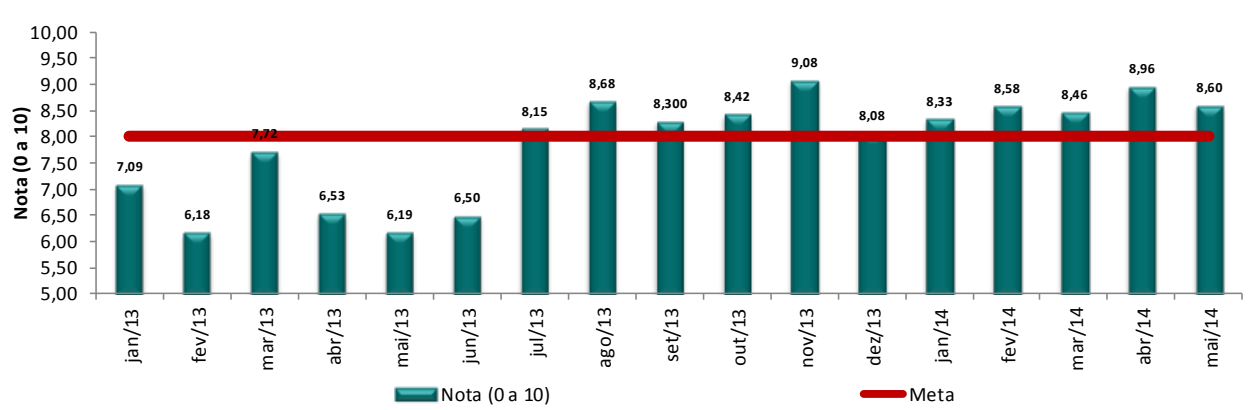

Teor de contaminantes por Raio-X

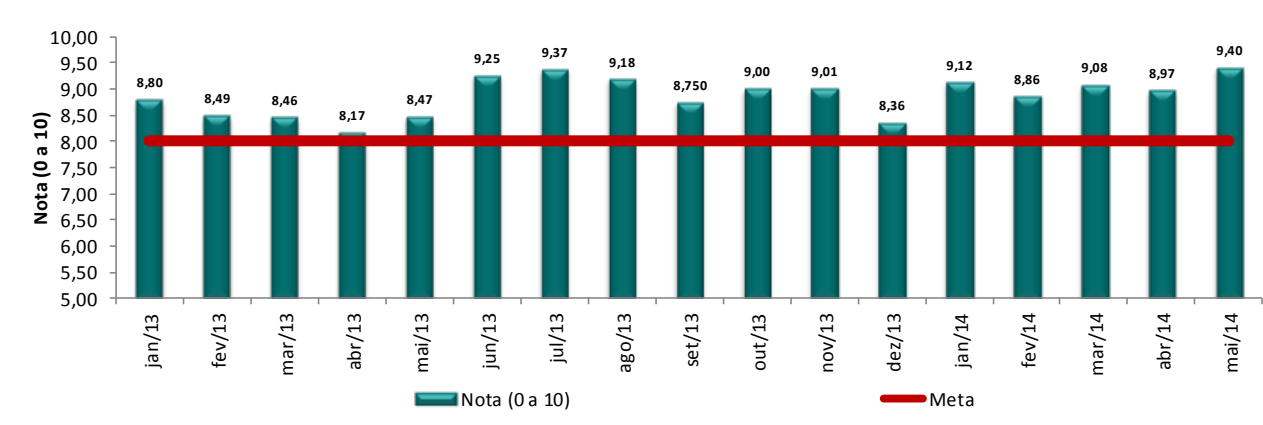

Teor de perda por calcinação (PPC)

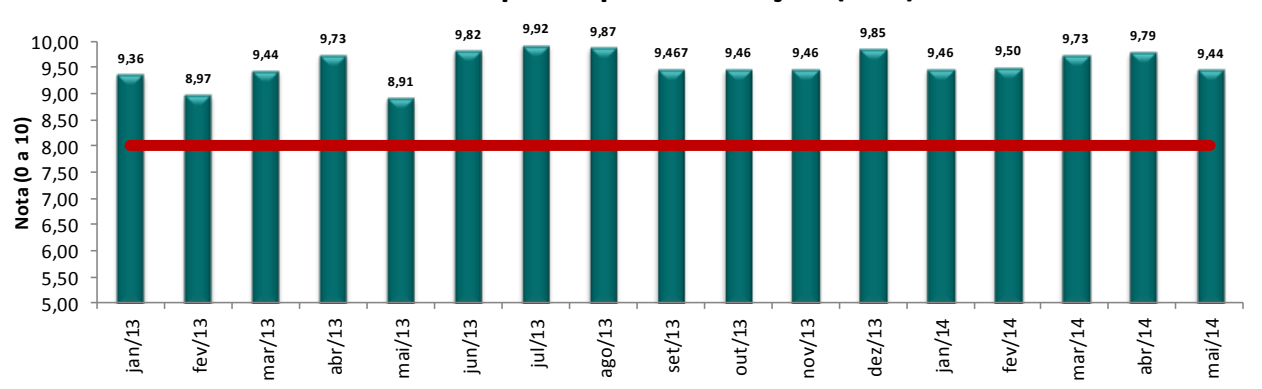

Figura 2: Gráficos da evolução de desempenho do indicador de Confiabilidade Metrológica dos laboratórios

* Contribuição técnica ao 44 Seminário de Redução de Minério de Ferro e Matérias-primas,

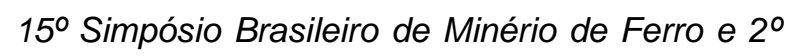
Simpósio Brasileiro de Aglomeração de Minério de Ferro, 15 a 18 de setembro de 2014, Belo Horizonte, MG, Brasil. 
A partir dos resultados verificou-se que há certa similaridade quando ao desempenho nas análises em $R X$ e na análise de PPC e que há diferença significativa de desempenho na análise de ferro via úmida. Diante do diagnóstico foram dispendidos mais esforços para melhorar a exatidão desta análise.

Atribui-se o fato de haver diferença de desempenho entre os laboratórios ao fato de já se ter havido um programa de melhoria da análise de ferro e monitoramento periódico de desempenho de operadores em período anterior à implantação deste método, apenas no laboratório do porto.

\subsection{Ações para Melhoria de Desempenho na Análise do Teor de Ferro na Mina}

Atenção especial foi dada à análise do teor de ferro em minério de ferro, pois a determinação de seu teor depende da percepção visual do operador que identifica o ponto final de cada uma das etapas de titulação, o que reforça a necessidade de avaliar pessoas quanto à veracidade e precisão das análises que executam.

1) Inicialmente fez-se uma apresentação para equipe com dois objetivos:

- Apresentar o objetivo da implantação do indicador, o status de desempenho atual, a meta e a trajetória para seu atingimento.

- Treinamento teórico sobre o método de analise aonde houve explicação de cada etapa da análise e se colocou em pauta os pontos críticos, nos quais havia possibilidade de haver problemas de precisão ou tendência, de forma a possibilitar maior maturidade técnica da equipe. Esta passou a se auto avaliar diante das explicações fornecidas.

2) Foram entregues dez amostras codificadas para cada um dos operadores que as analisaram logo após o treinamento. De posse dos resultados, foi promovido um diálogo individualizado com responsável técnico do laboratório cujo objetivo foi identificar as causas que levaram ao desempenho obtido e verificar se o conteúdo passado foi assimilado e aplicado na rotina.

3) Como houve melhoria de despenho em alguns operadores e em outros não, solicitou-se que um dos operadores, que teve bom desempenho, acompanhasse os demais observando minuciosamente as diferenças entre as práticas de cada um que poderiam ser causa do mau desempenho.

4) Após esta ação verificou-se que havia certas particularidades de ações por operador que o procedimento operacional escrito não conseguia padronizar. Então se elaborou um vídeo com o objetivo de equalizar o procedimento de análise

Passou-se a avaliar os resultados e fornecer feedback mensalmente. Observou-se que as melhorias por operador se deram em momentos diferentes. Uns desenvolveram a habilidade mais rápido que outros.

Diante disto, houve um direcionamento para dedicação exclusiva dos melhores operadores na análise de ferro e realocação dos demais para as demais análises.

Os operadores com menor desempenho continuaram fazendo suas análises-testes até desenvolver destreza similar aos com melhor desempenho. Observou-se evolução no desempenho global a partir do segundo semestre de 2013.

Dentro da gestão do laboratório, a melhoria da qualidade também levou a uma diminuição de custos, devido à redução do retrabalho, erros e atrasos, e da melhor utilização da tecnologia e matéria-prima.

\footnotetext{
* Contribuição técnica ao 44 Seminário de Redução de Minério de Ferro e Matérias-primas, $15^{\circ}$ Simpósio Brasileiro de Minério de Ferro e 2 Simpósio Brasileiro de Aglomeração de Minério de Ferro, 15 a 18 de setembro de 2014, Belo Horizonte, MG, Brasil.
} 


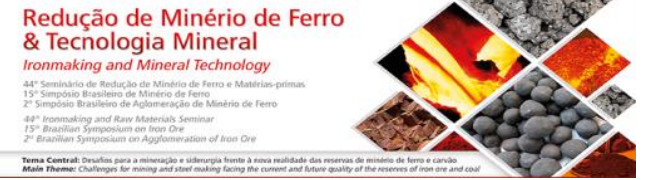

\section{CONCLUSÕES}

Avaliando-se o resultado do indicador secundário "confiabilidade metrológica" e dos indicadores primários que o compõe, foi possível identificar os pontos fortes e oportunidades de melhoria de cada laboratório, análise e operador, e tomar ações para melhoria dos sistemas de medição.

Identificou-se a oportunidade de melhoria mais significativa, que foi a análise de ferro via úmida no laboratório da mina. Iniciou-se um processo de capacitação e acompanhamento do processo que resultou na criação de uma escala de atividades por turno. Houve o direcionamento dos operadores com melhor desempenho na análise de ferro para executar preferencialmente esta análise até que todos os operadores atingissem mesmo nível de desempenho.

Com a identificação das oportunidades de melhorias de cada operador, foi possível direcionar a capacitação ou orientação individualizada, baseada nas boas práticas observadas nos operadores de melhor desempenho.

O trabalho alcançou os resultados esperados, pois por meio dele foi possível: conhecer o desempenho de cada análise e operador; identificar os pontos fortes para tomar as devidas ações; equalizar a forma de executar cada uma das tarefas com as melhores práticas identificadas. Os operadores evoluíram tecnicamente, saindo de um patamar de executantes de procedimento operacional para um profissional atendo às nuanças das análises executadas, tomando consciência da importância que seu trabalho na cadeia produtiva da empresa.

\section{BIBLIOGRAFIA}

1 Falconi CV. TQC Controle da Qualidade Total (No Estilo Japonês), 1a‥ed. Belo Horizonte: Fundação Cristiano Ottoni. 1992. 229p.

2 Falconi CV. Gerenciamento Pelas Diretrizes (Hoshin Kanry). 2ª .ed. Belo Horizonte: Fundação Cristiano Ottoni, 1996. 334p.

3 Hunter JC. Como se tornar um lider servidor: os princípios de liderança de "O monge e o Executivo". 2004. 6a ed: SEXTANTE. 144 p.

4 ISO 2597-2: Minério de ferro - Determinação do Teor de Ferro Total - Parte 2.

5 ISO 3082 - Minério de ferro - Procedimentos de amostragem e preparação de amostras.

6 ISO 3085 - Métodos experimentais para verificação da precisão de amostragem, preparação de de amostras e medida.

7 ISO 9001: Sistemas de gestão da qualidade - Requisitos.

8 ISO 17025: Requerimentos gerais para Laboratórios de Ensaio e Calibração.

9 Kardec A, Flores J, Seixas E. Gestão Estratégica e Indicadores de Desempenho. 1ª .ed. Rio de Janeiro: Qualitymark, 2002. 98p.

10 Montgomery D. Introdução ao controle estatístico da qualidade. $4^{\mathrm{a}}$ ed. LTC- Livros Técnicos Científicos, 2004.

11 Ribeiro JLD, Caten CST. Série Monográfica Qualidade: Controle Estatístico do Processo. Porto Alegre: FEENG/UFRGS, 2010.

12 Tadachi N., Flores MCX. Indicadores da Qualidade e do Desempenho. 1ª.$e d$. Rio de Janeiro: Qualitymark, 1997. 100p.

13 VIM - 2008 - Vocabulário Internacional de Metrológica.

14 Deming W. Edwards. Qualidade a revolução da administração. Rio de Janeiro: Marques Saraiva, 1990.

\footnotetext{
* Contribuição técnica ao 44 Seminário de Redução de Minério de Ferro e Matérias-primas, 15은 Simpósio Brasileiro de Minério de Ferro e 2 Simpósio Brasileiro de Aglomeração de Minério de Ferro, 15 a 18 de setembro de 2014, Belo Horizonte, MG, Brasil.
} 